\title{
Technical and business economic study of photovoltaic systems
}

\author{
B. Verhelst ${ }^{1,2}$, J. Desmet $^{1,2}$, C. Debruyne ${ }^{1,2}$, H. Van Landeghem ${ }^{3}$ and L. Vandevelde ${ }^{2}$ \\ ${ }^{1}$ HOWEST, Department GKG \\ Graaf Karel de Goedelaan 5, B-8500 Kortrijk (Belgium)
}

Phone:+ 325624 12 35, e-mail: bart.verhelst@ howest.be, jan.desmet@ howest.be, colin.debruyne@ howest.be

\author{
${ }^{2}$ Ghent University, Department EESA \\ Sint-Pietersnieuwstraat 41, B-9000 Ghent (Belgium) \\ Phone: +32 926434 22, e-mail: lieven.vandevelde@ ugent.be \\ ${ }^{3}$ Ghent University, Department Industrial Management \\ Technologiepark 903, B-9052 Zwijnaarde (Ghent) (Belgium) \\ Phone: +32 926455 02, e-mail: hendrik.vanlandeghem@ugent.be
}

\begin{abstract}
Renewable energy becomes more and more important in our power supply. The aim of this study is to perform a business economic evaluation of an investment in photovoltaic (PV) energy. Different cases of PV projects have been analyzed. In order to have a correct evaluation model, both economic parameters and technical influences have to be taken into account. This paper gives an overview and a sensitivity analysis of the influencing parameters, as well as an analysis of a practical case. A calculation tool is developed to allow private persons and companies to determine the feasibility of an investment in photovoltaic panels. It can be concluded that not only economic parameters such as discount rate but also technical parameters have a major impact on the feasibility of an investment in photovoltaic energy.
\end{abstract}

\section{Key words}

solar power, economics, photovoltaic energy, efficiency, case study

\section{Introduction}

The majority of the private persons and (small) companies have little to no consciousness on the effectiveness and feasibility of renewable energy source projects. Their investment decisions are based on the knowledge and advice of installers of renewable energy systems. Analysis of different cases has shown that most of the installers only propose a simple payback time. This payback time is underestimated due to neglecting technological, environmental and economic parameters. This study should give the decision maker a tool and sufficient background in order to make a correct investment decision.

\section{Technical study}

Because of the increased interest in solar power, a lot of research has been done in order to increase the performance of these systems. There are several technologies and possibilities to install solar panels, each having their own efficiency and, as a consequence, a different yield. The first step in the analysis is a market study on the availability of existing and new technologies, including the influence with respect to the overall efficiency on PV-systems [1], [2]. Table I gives a summary of the most used technologies and their efficiencies in lab and production environment.

Table I - Efficiency of solar panels

\begin{tabular}{|l|c|c|}
\hline & Lab efficiency & $\begin{array}{c}\text { Production } \\
\text { efficiency }\end{array}$ \\
\hline monocrystalline & $24 \%$ & $14-17 \%$ \\
\hline polycrystalline & $18 \%$ & $12-15 \%$ \\
\hline amorphous $\mathrm{Si}$ & $13 \%$ & $5-7 \%$ \\
\hline
\end{tabular}

Besides panel efficiency, both inverter and panel inclination have a major influence on the system yield. Inverter efficiencies are usually between $90 \%$ and $95 \%$. A deviation of $10^{\circ}$ with respect to the optimal panel inclination angle can result in a difference in yield of 5 to $10 \%$ [4]. Positioning systems affect the system yield, depending on the type of installation (Table II).

Table II - increased yield tracker vs. fixed system [5]

\begin{tabular}{|l|c|}
\hline & Increased yield \\
\hline Single axis - horizontal (east-West) & $0-21 \%$ \\
\hline Single axis - horizontal (north-south) & $0-31 \%$ \\
\hline $\begin{array}{l}\text { Single axis - vertical (under optimum } \\
\text { angle) }\end{array}$ & $11-55 \%$ \\
\hline Single axis (south) & $12-50 \%$ \\
\hline Double axis & $10-55 \%$ \\
\hline
\end{tabular}


Depending on the type of technology more or less surface area will be needed in order to generate the same amount of energy [3].

Besides technical parameters the availability of solar radiation is one of the major factors that influence the total yield. The amount of solar radiation that falls into the panel surface depends on the region of installation (Figure 1) and the declination of the panel vs. the optimum (Figure 2) [5].

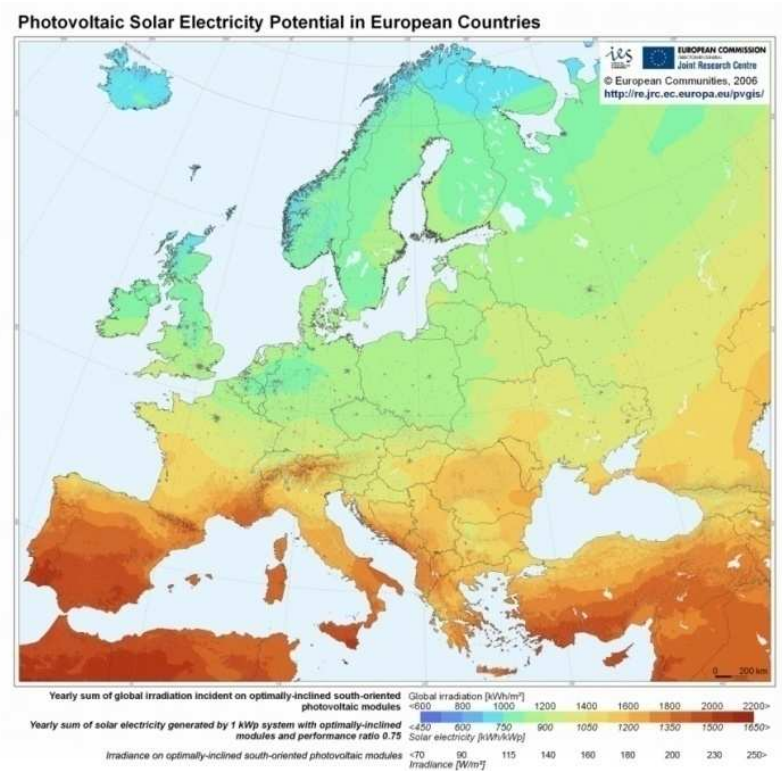

Figure 1: yearly sum of global irradiation on optimally inclined south oriented photovoltaic modules [5]
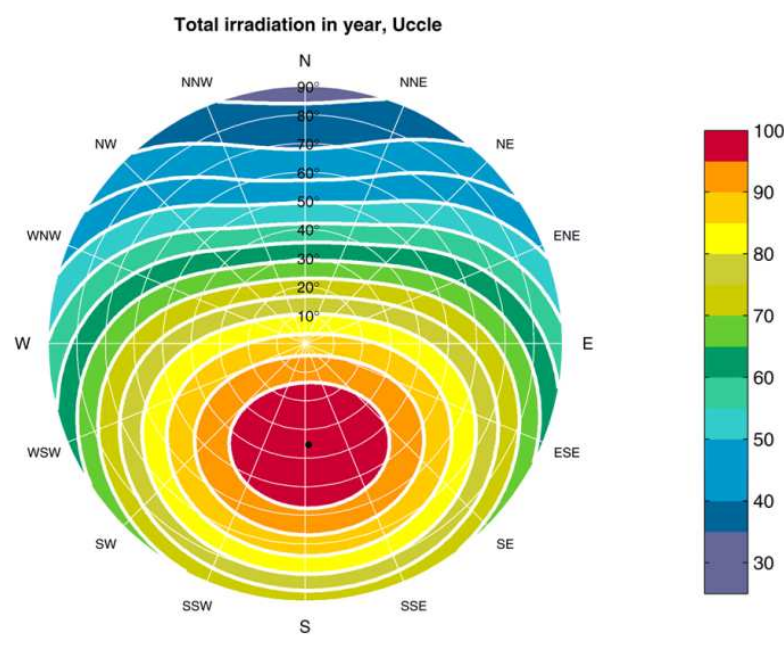

$\cdot=$ maximum $\left(1083 \mathrm{kWh} / \mathrm{m}^{2}\right)$ at orientation $=-2^{\circ}$ tilt $=35^{\circ}$ contour levels in \% of
maximum ( $5 \%$ interval)

Figure 2: total irradiation in Uccle (Belgium) and decrease in yield contours [10]

In this study the total yield is based on the amount of radiation per area that falls into the panel. Together with the panel efficiency a yield per area can be determined.

Example:

A panel with capacity of $220 \mathrm{Wp}$ and $1,59 \mathrm{~m}^{2}$ corresponds to $7,23 \mathrm{~m}^{2} / \mathrm{kWp}$. With a radiation of 1080
$\mathrm{kWh} / \mathrm{m}^{2} /$ year and panel efficiency of $12 \%$, this panel gives $937 \mathrm{kWh} / \mathrm{kWp}$ with optimal inclination.

Furthermore, different other parameters such as pollution, shade and temperature have a noticeable effect on the overall efficiency. The combined influence of these small losses can be significant.

The yield of a solar panel can be calculated by the following expression.

$$
\begin{aligned}
E_{L}= & H_{i} \cdot A_{\text {panel } 1 k W p} \cdot \eta_{\bmod u l e} \cdot \eta_{\text {inv }} \cdot \eta_{\text {inclination }} \\
& .\left(1-\eta_{\text {cable }}\right) \cdot\left(1-\eta_{\text {mismatch }}\right) \cdot\left(1-\eta_{\text {temp }}\right) \\
& .\left(1-\eta_{\text {pollution }}\right) \cdot\left(1+\eta_{\text {trac }}\right)
\end{aligned}
$$

where $E_{L}$ represents the solar panel yield $\left[\mathrm{kWh} / \mathrm{kW}_{\mathrm{p}}\right], \mathrm{H}_{\mathrm{i}}$ the global irradiation $\left[\mathrm{kWh} / \mathrm{m}^{2}\right], \mathrm{A}_{\text {panel } 1 \mathrm{kWp}}$ the panel area for $1 \mathrm{kWp}\left[\mathrm{m}^{2}\right], \eta_{\text {module }}$ the module efficiency, $\eta_{\text {inv }}$ the inverter efficiency, $\eta_{\text {inclination }}$ the inclination efficiency, $\eta_{\text {cable }}$ the cable losses, $\eta_{\text {temp }}$ the temperature losses, $\eta_{\text {pollution }}$ the shadow and pollution losses, $\eta_{\text {mismatch }}$ the mismatch losses and $\eta_{\text {trac }}$ the tracker efficiency (increased efficiency compared to fixed position).

Installers only take into account the inclination when calculating the yield, resulting in deviations of $10-15 \%$. This significant deviation underlines the importance of a correct calculation of the systems yield. The overall yield forms the basis for further economic evaluations.

\section{Economic study}

The second part of the study is the economic evaluation of the system.

\section{A. Economic decision rules}

First, an analysis is performed with respect to the economic decision rules. The obtained results show that Net Present Value (2) and Internal Rate of Return (3) methods are the most correct approaches in order to make economic evaluations. These calculations are based on free cash flow (FCF) [6]:

$$
\mathrm{NPV}=-I+\sum_{j=1}^{N} \frac{\mathrm{FCF}_{j}}{(1+i)^{j}}
$$

where I represents the investment costs, $\mathrm{FCF}_{j}$ the free cash flow in year $j$ and $i$ the discount rate.

$$
-I+\sum_{j=1}^{N} \frac{\mathrm{FCF}_{j}}{(1+k)^{j}}=0
$$

where $\mathrm{k}$ represents the internal rate of return.

Installers mostly use the Simple Payback Period method (SPP) (4) and do not put effort into correct FCF calculations: 


$$
\mathrm{SPP}=T \quad \text { if } \quad \sum_{j=0}^{T} \mathrm{FCF}_{j}=I
$$

It is obvious that the constituent parts of the cash flow must be determined before further calculations can be made. The free operational cash flow can be determined by means of following framework.

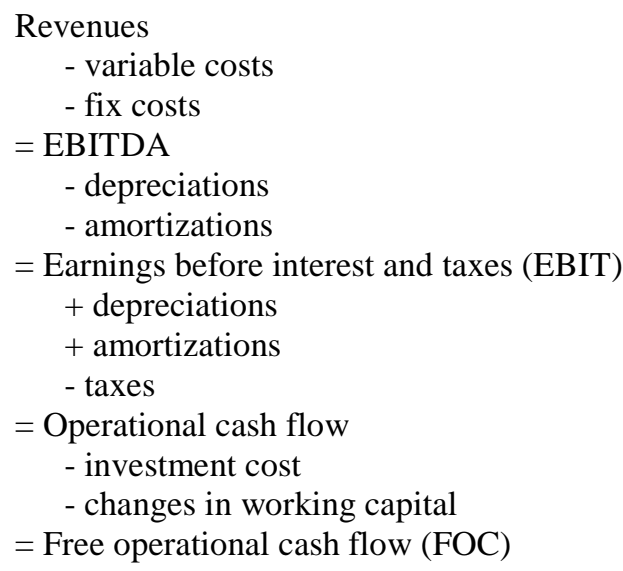

The discount rate used for companies is the weighted average cost of capital (WACC) [5].

$$
\mathrm{WACC}=\frac{E}{(E+D)} * \operatorname{Re}+\frac{D}{(E+D)} * \mathrm{Rd} *(1-t)
$$

where $E$ and $D$ represents the market value of the firm's equity / debt, $R e$ the cost of equity, $R d$ the cost of debt and $t$ the corporate tax rate.

For private persons the assumed discount rate is the return on a state obligation for 10 years when investment is made with capital equity (For Europe approx. 4\% [7]) and the interest rate when investing with a loan.

\section{B. Investment in photovoltaic systems}

The most important economic factors such as income, cost and grants need to be defined. Income is composed of both refunding of produced electricity and government grants. An important factor is the different energy price used for both the refunding of the produced energy and the reduction of purchased energy. This parameter can have a major influence on the payback time of the project. The division between peak hours and off-peak hours is made by means of a solar profile where a division is made between the different types of production hours [8]. The total yield of electricity is determined by (6). Because pricing in Belgium is different week - weekend / day - night a distinction is made in the expression.

$$
\begin{aligned}
\text { profit } & =\left(\mathrm{TP} * \% \mathrm{P}_{w} * \% \mathrm{OC}_{w} * € / \mathrm{kWh}_{p p}\right) \\
& +\left(\mathrm{TP} * \% \mathrm{P}_{w} * \% \mathrm{~S}_{w} * € / \mathrm{kWh}_{s p}\right) \\
& +\left(\mathrm{TP} * \% \mathrm{P}_{w e} * \% \mathrm{OC}_{w e} * € / \mathrm{kWh}_{p o}\right) \\
& +\left(\mathrm{TP} * \% \mathrm{P}_{w e} * \% \mathrm{~S}_{w e} * € / \mathrm{kWh}_{s o}\right)
\end{aligned}
$$

Where TP represents the total annual electricity production of the local production unit, $P_{w}$ the percentage production during the week, $\mathrm{OC}_{w}$ the percentage on site consumption during the week, $€ / \mathrm{kWh}_{\mathrm{pp}}$ the purchase cost of electricity peak hours, $S_{w}$ the percentage electricity sold during the week, $€ / \mathrm{kWh}_{\mathrm{sp}}$ the sales revenue of electricity peak hours, $P_{w e}$ the percentage production during the weekend, $\mathrm{OC}_{w e}$ the percentage on site consumption during the weekend, $€ / \mathrm{kWh}_{\mathrm{po}}$ the purchase cost of electricity in off peak hours, $S_{w e}$ the percentage electricity sold during the weekend, $€ / \mathrm{kWh}_{\mathrm{so}}$ the sales revenue of electricity in off peak hours.

Also the granting mechanisms of both local and federal government are very important. Most of the projects are not feasible without these support mechanisms. Examples of these mechanisms are earnings on $\mathrm{CO}_{2}$ certificates or green power certificates but also tax reduction measures.

Costs mainly consist of the investment cost but also in the replacement of components outside warranty, costs for annual maintenance and recycling costs.

It is important to make a distinction in warranty. Especially the difference between factory warranty and efficiency warranty is often neglected. Factory warranty is usually $\mathbf{5}$ years where efficiency warranty is usually 20 years. Also the inverter warranty is important. This is usually 5 years where the life time is around 8 years. This means that during the life time of the project there is a big chance that the inverter will need replacement.

When all of these factors are known, they can be implemented in the economic model.

\section{Calculation tool}

A calculation tool is developed to allow private persons and companies to determine the feasibility of an investment in photovoltaic panels.

The software calculates, for a specific situation, the NPV and IRR. The software is applicable for both private persons and companies. Both modules accommodate specific content for each target group for example grand mechanisms and tax deduction measures.

Generally following information is required:

- Technical parameters of the installation (size, irradiation, ...)

- Investment information (costs)

- Economic parameters (WACC, ...)

- Grants and tax deduction measures 
For companies an additional module is added to allow the user to implement a user specific profile so that even production times can be taken into consideration for calculation.

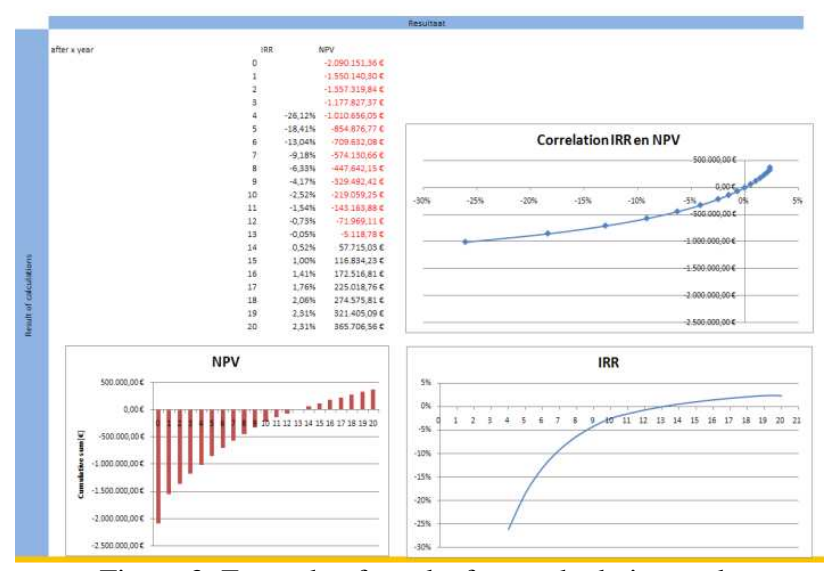

Figure 3: Example of results from calculation tool

\section{Case study}

As practical implementation of the research results, several case studies have been worked out. One of them is a printing business near Antwerp (Belgium) where several options for placing solar power have been taken into account. These options included installations on several types of roofing and tracker systems. In a first step, the company performed research on what kind of installation is possible and what the costs are because of the different roof coverings. For some additional cost had to be made to reinforce or repair roofing caused by wear and tear. For this the company received offers from different installers. After elimination based on practical possibilities, investment cost ( $€ / \mathrm{Wp}$ ) and offered service three PV installations of different capacity remained out of 14 offers. The payback time and investment cost of the different offers is summarized in Figure 4.

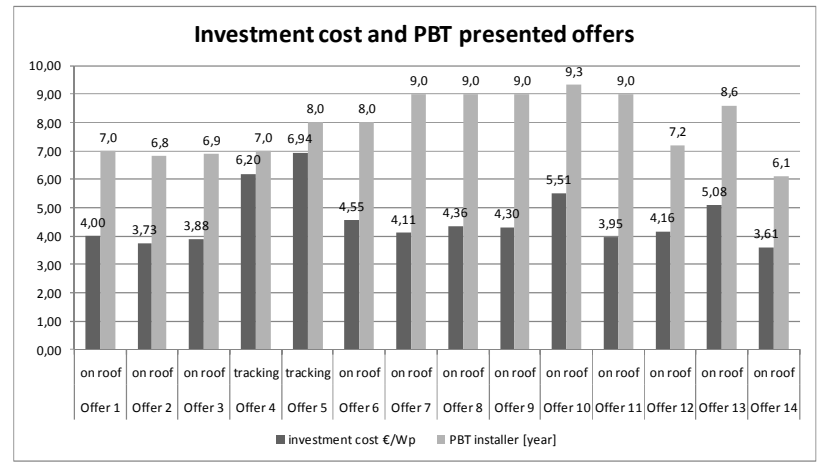

Figure 4: investment cost and PBT presented offers

In a second step, the remaining offers are further evaluated, taking into account technical (installed power, panel efficiency, inclination angle and correction factors for temperature, shade, cable losses,...) and economical parameters (investment data, energy price, discount rate, government grants,...).

The payback time of the offered solutions and the calculated payback times are given in Figure 5.

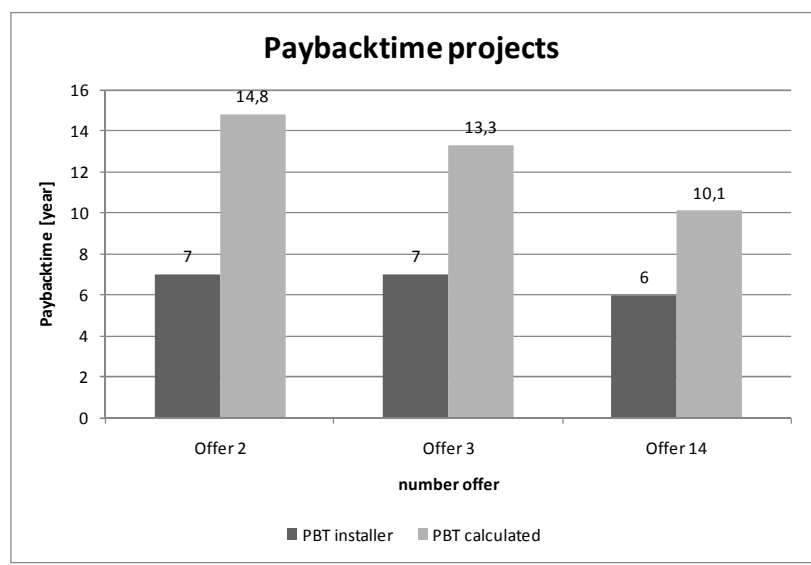

Figure 5: Payback times projects

The difference in results is mainly caused because the installer does not take in consideration the above mentioned factors. Specifically for this case these are the following factors.

1. Net energy yield: the installer only calculates based on a yield of $1000 \mathrm{kWh} / \mathrm{kWp} /$ year and a correction for the orientation $(95 \%)$, resulting in a net yield of $950 \mathrm{kWh} / \mathrm{kWp} /$ year. The calculations based on this research give that there is a radiation of $1100 \mathrm{kWh} / \mathrm{m}^{2} /$ year applicable for that region. Based on the area per peak power and the panel efficiency the yield per peak power is calculated. (see example technical study). For this case the yield is 954 $\mathrm{kWh} / \mathrm{kWp} /$ year. On this yield, a correction for the orientation (95\%), inverter efficiency (95\%), temperature $(2 \%)$, pollution $(3 \%)$, cable losses $(1 \%), \ldots$ is applied [3], resulting in a net yield of $810 \mathrm{kWh} / \mathrm{kWp} /$ year. Additionally a drop of efficiency $(1,1 \%)$ is applied every year.

2. Price difference between peak hours $(0,12$ $€ / \mathrm{kWh})$ - and off-peak hours $(0,08 € / \mathrm{kWh})$. The installer makes his calculation only taking peak hour tariff into consideration where the calculation tool takes into account both peak and off-peak hours.

3. Following the previous, the calculation tool makes a difference between the amount of production / own consumption during peak and off-peak hours. For this case, $70 \%$ of the total production is during the week and $30 \%$ during the weekend. During the week $85 \%$ of the production is used inside the company, during the weekend $11 \%$. The surplus produced energy is sold to the electricity supplier.

4. Additional costs such as operating and maintenance costs are considered by the software but not in the installer's calculations. These costs are an assumption dependent on the size of the installation and the size of the organization. Usually a small percentage is taken of the installation cost $(1 \%)$. To consider inflation an annual increase of $2 \%$ is taken.

5. Economic payback calculations are based on a SPB in the installers calculations where the software uses NPV (2) with the actual WACC (5) of the firm (in this case 7,5\%). 
The case study shows a realistic payback time of almost the double of what installers calculate (Figure 5).

\section{Sensitivity analysis}

Figure 6 shows the influence of several technical and economical parameters on the payback time of a PV system.

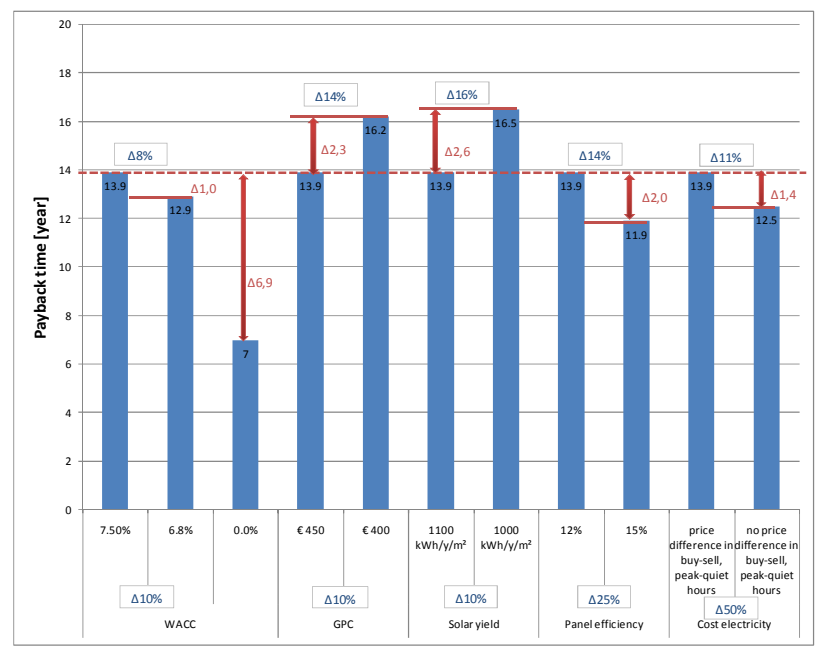

Figure 6: Influence of several technical and economical parameters on the payback time of a PV system

Installers generally indicate payback times of 6 to 7 years. However, in reality it will be almost twice, taking into account all parameters. The sensitivity analysis shows the impact of the different parameters on the payback time.

Sensitivity analysis shows that the implementation of the discount factor WACC has large impact on the payback time. As a consequence payback times can be double when using a realistic WACC against a WACC of $0 \%$. The influence of other parameters such as government grants, solar yield a panel efficiency also should not be underestimated.

\section{Conclusion}

This study gives the decision maker a tool to perform a profound economic-technical analysis of a possible investment in PV installations. Many installers state that photovoltaic solar energy is profitable in the short term. However, this has to be treated cautiously since a lot of influencing parameters must be taken into account. Where installers indicate payback times of 6 to 7 years, in reality it almost will be twice, taking into account all factors. Sensitivity analysis shows that the discount rate and the panel yield are the most sensitive factors. The panel yield is determined by the different efficiency parameters.

It can be concluded that not only economic parameters such as discount rate but also technical parameters have a major impact on the feasibility of an investment in photovoltaic energy. Consequently, all parameters should be taken into account for a correct evaluation.

\section{Further work}

Further detailed calculations will also implement the production losses due to overvoltage [9]. This will have further negative impact on the payback time especially in residential installations.

\section{References}

[1] M. Imamura, P. Helm and W. Palz. "Photovoltaic System Technology: European Handbook”, ed. UK: HS Stephens \& Associates, 1992.

[2] NREL, (2005). "Best research cell efficiencies." Available on http:// www.nrel.go/pv/thin_film/docs/kaz_best_research_cells.ppt

[3] PV. Monitoring - novem. (2009). "Begrippenlijst PVsystemen." Available on http://www.pv-monitoring.novem.nl/contents/BL1.html

[4] PVGIS European Communities. (2001-2008,). "Irradiation in Europe." Available on http://re.jrc.ec.europa.eu/pvgis/ download/download.htm

[5] T. Huld, et al., "Comparison of Potential Solar Electricity Output form Fixed-Inclined and Two-Axis Tracking Photovoltaic Modules in Europe", ed. Wiley InterScience: Wiley \& Sons, Ltd, 2007, p. 13.

[6] S.A. Ross, R.W. Westerfield, B.D. Jordan, Fundamentals of Corporate Finance, McGraw-Hill, 2000

[7] DNB, (2009, 16 februari 2009), "Overzicht evolutie Rendement 10-jaars staatslening eurogebied, VS en Japan",

Available: http://www.statistics.dnb.nl/index.cgi?lang=nl\&todo=Rente $\mathrm{s}$

[8] R. Dogniaux, M. Lemoine, R. Sneyers. "Annee type moyenne pour le traitement de problems de capration d'energie solaire”, KMI, 1978

[9] C. Debruyne, J. Desmet, J. Vanalme, B. Verhelst, G. Vanalme, L. Vandevelde. "Maximum power injection acceptance in a residential area", accepted for ICREPQ 2010.

[10]Total irradiation in Uccle (2009, 10 November 2009), http://www.waassolar.be/default.asp?p=7

\section{Authors}

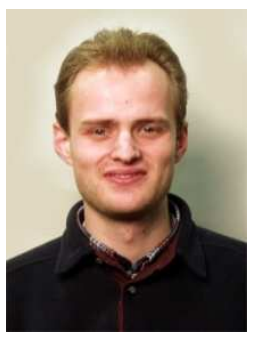

Bart Verhelst received his Master in Industrial Sciences degree in Electromechanics - Electrotechnical Engineering from the Technical University College HoWest, Kortrijk, Belgium, in 2004, and received his Masters degree in Industrial Management from the University of Ghent, Ghent, Belgium, in 2009.

Since 2004 he is a full time researcher at the University College HoWest, Kortrijk, Belgium, mainly in the field of power quality, renewables and electrotechnical engineering. In 2009 he added economics to his field of research. He is member of the Institute of Industrial Engineering (IIE).

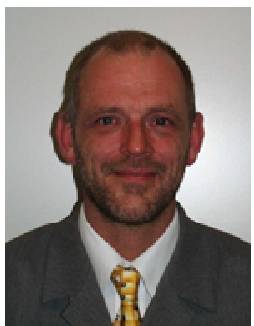

Jan J. M. Desmet (M'01) received the polytechnical engineer degree from the polytechnic in Kortrijk Belgium in 1983, the M.S degree in electrical engineering in 1993 from the V.U.Brussels Belgium and in 2008 his $\mathrm{PhD}$ degree at the KULeuven, Belgium. Since 1984 he is member of the staff of the University 
College HoWest, Kortrijk. Currently he is full professor at the University College HoWest, Kortrijk, Belgium teaching power quality, renewables and industrial electric measurement techniques. His research interests include energy efficiency, renewable, power quality and their mutual interactions. He is also IASTED and IEEE member, member of SC77A (IEC) and TC210 (CENELEC).

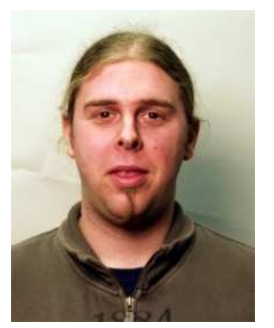

Colin Debruyne received his Master in Industrial Sciences degree in Electromechanics - Electrotechnical Engineering from the University College HoWest, Kortrijk, Belgium, in 2004. Since 2004 he has been a researcher at the University College HoWest, Kortrijk, Belgium, mainly in the field of power quality and general electrotechnical engineering. Since '09 he is a Ph.D. student at Ghent University, Ghent, Belgium, where he is working on improving the magnetization of permanent magnet synchronous motors by supplying a non sinusoidal wave shape.

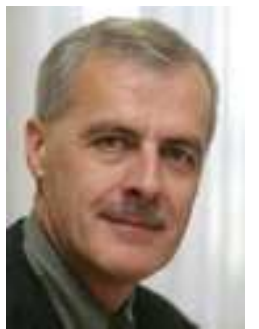

Hendrik Van Landeghem is full professor in Industrial Management at Ghent University. He is an expert in the area of logistics and their application in business processes. He advises companies in their choice and implementation of their logistic organization and production control systems. He is fellow of the European Academy of Industrial Management (AIM) and senior member of the Institute of Industrial Engineering (IIE). He is since 2007 Fellow of the World Confederation of Productivity Science.

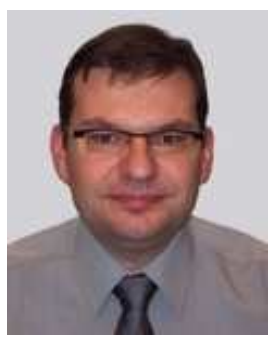

Lieven Vandevelde was born in Eeklo, Belgium in 1968. He graduated in electromechanical engineering at Ghent University in 1992 and is since then with the Electrical Energy Laboratory (EELAB). He received the Ph.D. degree from Ghent University in 1997. Since 2004, he is professor in electrical power engineering. His research and teaching activities are in the field of electrical power systems, electrical machines and (computational) electromagnetics. 